\title{
Research on Beautiful Village Planning of Resettlement Sites in Mountain Villages of Yichang

\author{
Lin $\mathrm{CHEN}^{1, *}$, Wan ZHU ${ }^{2}$ and Wei-jia YIN²
}

${ }^{1}$ Reservoir Resettlement Research Center of China Three Gorges University, Yichang, Hubei, China

${ }^{2}$ China Three Gorges University, Yichang, Hubei, China

${ }^{*}$ Corresponding author

Keywords: Mountain Villages; Resettlement Sites Planning; Beautiful Village; Anti-Poverty by Relocation.

\begin{abstract}
The construction of beautiful village is an important starting point to solve the "three rural issues" and an important measure to realize the "Chinese dream". Under the background, the resettlement is an important means of poverty alleviation in the western Hubei mountain area. Through the analysis of the construction of the resettlement sites in Yichang in recent years, it is concluded that the problems of improper location, insufficient industry support, serious ecological environment destruction, great difficulty of cultural integration and lagging of facilities construction are put forward. And it is proposed that planning strategies should be based on location, industry, ecology, culture, facility and so on. In order to provide a reference for the construction of resettlement sites in the future, this paper conducts empirical research on Shahe village in Niuzhuang township of Yichang.
\end{abstract}

\section{Introduction}

The construction of resettlement sites is a systematic project. Under the background of completing the building of a moderately prosperous society in all respects, the planning and construction of resettlement sites are undergoing some changes in the concept of building a beautiful village. At present, scholars have studied the location of resettlement sites and infrastructure construction. CHEN Lin mainly considers the location, landform utilization, planning layout and infrastructure of resettlement sites, and puts forward corresponding planning principles. [1] FENG Ming-su and PENG Jie reflect on the site selection of ecological resettlement sites in mountainous areas, and put forward that in the selection process of resettlement sites, we should choose as far as possible the living mode of "back to the mountains and face the water". [2] ZHANG Shu-qing summarizes the experience of resettlement sites construction, believing that the resettlement sites should focus on infrastructure construction, housing construction and landscape building, etc. [3] LIU Yong-xin thinks that the key points of resettlement sites planning are infrastructure such as roads, water supply and drainage, electricity and so on. [4] This paper studies the resettlement sites planning of mountain villages from the aspects of location, industry, ecology, culture and facilities, hoping to provide reference for other similar areas.

\section{Relevant Background}

\subsection{Relocation of Poverty Alleviation}

At the 2015 high-level forum on poverty reduction and development, XI Jin-ping stressed the implementation of the "five batches" action plan for poverty alleviation, which clearly proposed to relocate a group of poor people through "relocation". In "the 13th five-year plan" program for relocation of poverty alleviation by land-change, it is proposed to use five years to implement the relocation of poverty-stricken people with file-building licensing in poverty-stricken areas, and promote coordinated development of economy, society and ecological environment in poverty-stricken areas. 


\subsection{Beautiful Village}

To build a beautiful China, we must build a beautiful village and avoid the spread of many "urban diseases" to the village. Generally speaking, the connotation of beautiful village is environmentfriendly and resource-saving. Its core is green, circular, low-carbon and sustainable. The key is low energy consumption, low emissions and pollution-free. Beautiful village should contain three basic levels, namely ecological beauty, living beauty and production beauty. [5]

\subsection{Features of Mountain Villages in Yichang}

Yichang is located at the boundary of the upper and middle reaches of the Yangtze River, in the transition zone where the western Hubei mountains meet the Jianghan plain, belonging to the western Hubei mountains typical mountain cities. The main features of mountain villages in Yichang are limited topography and landform, shortage of land resources and backward economic development. The natural environment is superior and the ecological foundation is good. With profound cultural deposits, rural regional culture is rich in connotation and distinctive features. Tourism resources are abundant, the facilities of public service facilities are inadequate, and tourism service industry is developing slowly.

\subsection{Problems in Resettlement Sites in Mountain Villages of Yichang}

Yichang, the capital of hydropower, is rare for its large-scale, wide-ranging, heavy-duty and long-lasting resettlement. The following problems exist in the construction of resettlement sites: inadequate industrial support and lagging development, inadequate protection of ecological environment, difficult integration of cultural customs, lagging infrastructure and public service facilities, etc.

\section{Planning Strategy}

\subsection{Ensuring Location Safety and Constructing Safe Villages}

The site selection of resettlement sites in mountain villages should take into account the topography and landform, water resources and other factors, carefully investigate the potential risk of natural disasters, ensure the safety of site selection and construct a safe village.

\subsection{Adhere to Industrial Poverty Alleviation and Constructing Fluent Villages}

The planning of resettlement sites in mountain villages should adhere to the industrial poverty alleviation, combine with the rural industrial planning, develop advantageous industries according to local conditions, carry out the economic construction mode of "one village, one product" in beautiful village, persist in industrial poverty alleviation and construct affluent villages.

\subsection{Protecting the Ecological Environment and Constructing the Poetic Village}

The environmental sanitation, architectural style and spatial layout of the settlement sites should be adapted to the construction of beautiful village, and the level of greening, brightening and beautifying of ecological environment should be constantly improved. The ecological greening and the construction planning of the resettlement sites should be placed in the same important position, so as to protect the ecological environment and construct a poetic village.

\subsection{Promoting Cultural Integration and Constructing Civilized Villages}

The planning of resettlement sites should comprehensively analyze the traditional culture and modern culture of the place of emigration, extract their cultural characteristics and organic integration, advocate cultural reconstruction, so as to alleviate the rural complex of immigrants and create a new rural culture.

\subsection{Improving Facilities and Constructing Livable Villages}

Perfect facilities system is not only the key work for immigrants to "move, stay, and get rich", but 
also the basic conditions for immigrants to get rid of poverty and get rich. This requires the integration of relevant resources in the process of resettlement, and effectively increases the investment in facilities. We should focus on strengthening the village-level public service system, improving facilities and constructing livable villages.

\section{Planning Practice of Resettlement Site in Shahe Village}

\subsection{Project Overview}

Shahe village is located in the northern part of Niuzhuang town, about $70 \mathrm{~km}$ away from Wufeng county. The Wuba road passes through the village and connects the surrounding villages. The pillar industries are planting vegetables and herbs, but the depth of development is not enough, and the industrial chain is short. The resettlement site is located in Shaheping residential area of Shahe village, about $2 \mathrm{~km}$ away from the township government residence, with a total land area of $1.692 \mathrm{hm}^{2}$, and a total of 100 people are resettled.

\subsection{Planning Countermeasures}

Location. Safety is the first, taking advantage of the situation and choose the location. The location of resettlement in Shahe village is based on principles of livability, disaster prevention, ecological protection and cultural respect. As the overall topography of Shahe village is complex, but the ecological foundation is good, and various factors are taken into account comprehensively, the gentle slope area with good geographical location is selected as the construction land for the resettlement. The land is flat and open, with few existing residents, close to the village road, adjacent to the town and the surrounding industries are well developed, which is in line with the relevant conditions for resettlement. The design tries to combine the original terrain of the terrace, pays attention to the coordination between the original ecology and the new order of the terrace, minimizes the excavation and filling engineering, and makes use of the existing topographic to plan the layout of the building.

Industry. Industry should be developed according to local conditions. Industrial development land is reserved in the west of the resettlement site. Relying on existing dominant industries such as planting and breeding, the primary industry is optimized, the secondary industry is moderately developed and the tertiary industry is coordinated.

Ecology. The ecology is the base, continuing the texture to shape the characteristic. Based on the protection of ecology, we explore the texture relationship between mountains, forests, fields, houses and landscapes. The planning, combined with topography and landform, divides the land into three platforms. The three platforms gradually rise from west to east to increase the overall sense of sequence, openness and staggered sense. The eastern mountain forest resources are introduced into the interior to increase the permeability of the mountain forest. It is connected with the farmland on the west side, forming a comfortable space in accordance with the situation of the mountain.

Culture. Culture is the root and culture remodeling activates endogenesis. Because of different customs and cultures, immigrants are easy to self-enclosed and cannot quickly integrate into the place of resettlement. Therefore, it is necessary to dig out the traditional culture of the village and Shahe village and reshape the culture to increase the cultural identity of immigrants. First of all, regular ideological communication meeting will be held to solicit opinions on the construction and management of resettlement sites so as to stimulate their sense of ownership. Secondly, because migrants are mainly poor families, we should promote the culture of rural virtuous people and set up advanced models of labor to motivate them to make progress. In addition, cultural exchange activities will be held regularly on the cultural plaza to invite villagers to share their rich experiences and views on village construction.

Facility. Facility oriented, improving people's livelihood and meeting needs. We will improve public services and infrastructure to create a harmonious and beautiful living space. About road traffic planning, the resettlement site is connected with surrounding villages and towns through the east-west 
Wuba road and a north-south village road within the base. The Wuba road is 6 meters wide and the village road is 3 meters wide. The village road will be widened to 3.5 meters wide, and the road will be fully hardening. Combining with the current topographic conditions, a 6-meter-wide trunk road is planned on the western edge of the planning area to facilitate the travel of the residents below the mountain. The 3.5-meter-wide sub-road is built in front of each row of houses to connect the trunk road in the planning area, so as to maximize the convenience of residents entering the home; About public facilities planning, as the base is adjacent to the township government residence and village committee, there are many public service facilities around, but there are few recreational facilities for the masses such as activity squares. The cultural activity square is set in the south of the planning area to provide the residents of the site with a place for sports, entertainment and cultural exchange, taking the topography conditions and the convenience of the villagers into consideration; About Infrastructure planning, the plan adopts the drainage mode of rain and sewage diversion, the rainwater is used by gravity self-flow in the terrain, and rainwater drainage ditches are set up along the road, the outside of the bunker and the front and back of the house. The sewage is collected to the septic tank and discharged into the artificial ecological wetland after treatment. Two garbage collection points are set up, the domestic garbage is cleaned regularly, and the garbage is collected by garbage. After collected by the garbage collection point, the garbage is transported to the township garbage transfer station, and then transported to the county garbage disposal site for sanitary treatment.

\section{Conclusion}

Based on the summary of the current situation of resettlement sites in mountain villages of Yichang, this paper puts forward the planning strategy of "safety, industry, ecology, culture, facilities" to improve the resettlement site's "hematopoietic" function, so as to achieve poverty alleviation and prosperity.

\section{Acknowledgement}

This project is "Research on the risk and countermeasures of urban resettlement of poverty alleviation migration". And this research is financially supported by the open fund of The Foundation of College's Key Research on Humanities and Social Science in Hubei-Reservoir Migration Research Center (Project No. 2017KF07).

\section{References}

[1] CHEN Lin, Thoughts on planning and layout of resettlement sites for hydropower projects [J]. Yangtze River, 2018 (19): 87-88+94.

[2] FENG Ming-fang, PENG Jie, Analysis and proposal on the selection of resettlement location for the migrations from mountain areas - take the migrations of southern of Shaanxi as an example [J]. Reformation \& Strategy, 2012, 28 (12): 97-99.

[3] ZHANG Shu-qing, Experience analysis of resettlement sites construction of angu hydropower station [J]. Industrial \& Science Tribune, 2017, 16 (10): 214-216.

[4] LIU Yong-xin, Planning and analysis of the concentrated resettlement site for land expropriation and resettlement of wugachong reservoir [J]. Heilongjiang Hydraulic Science and Technology, 2017, 45 (08): 141-143.

[5] CUI Li-xiang, The construction of beautiful villages: its connotation, problems and their countermeasures [J]. Journal of Huanghe S \& T University, 2016, 18 (03): 60-64. 